\title{
Order effects in category scaling of grays'
}

Irwin Pollaek

MENTAL HEALTH RESEARCH INSTITUTE, THE UNIVERSITY OF MICHIGAN

\section{Abstract}

Three studies demonstrate that category ratings of grays are strongly influenced by the order of stimulus presentation.

\section{Problem}

To examine the role of order effects in the category of grays.

\section{Experiment 1. Effect of Stimulus Drder}

Eleven gray papers - five light grays, an intermediate gray, and five dark grays-were presented one-at-atime for rating. Two different orderings were used: five light grays in a scrambled order, followed by the intermediate gray, and, followed by five dark grays in a scrambled order; or, the reverse ordering. Each of 31 Ss (British Naval Ratings) was presented with each temporal ordering in separate experimental sessions. Approximately half of the Ss started with each ordering. Most Ss had previously participated in other ratings of grays. All Ss in Exps. 1, 2, and 3 were tested individually with a rating scale from 1 (white) to 7 (black).

The large effect of temporal ordering is shown in Fig. 1. Initial presentation of the light set (circles) served to raise the entire intermediate range of the category scale; while initial presentation of the dark set (triangles) served to lower the entire intermediate range of the category scale. The insert represents the distribution of the 31 differences in ratings assigned to the

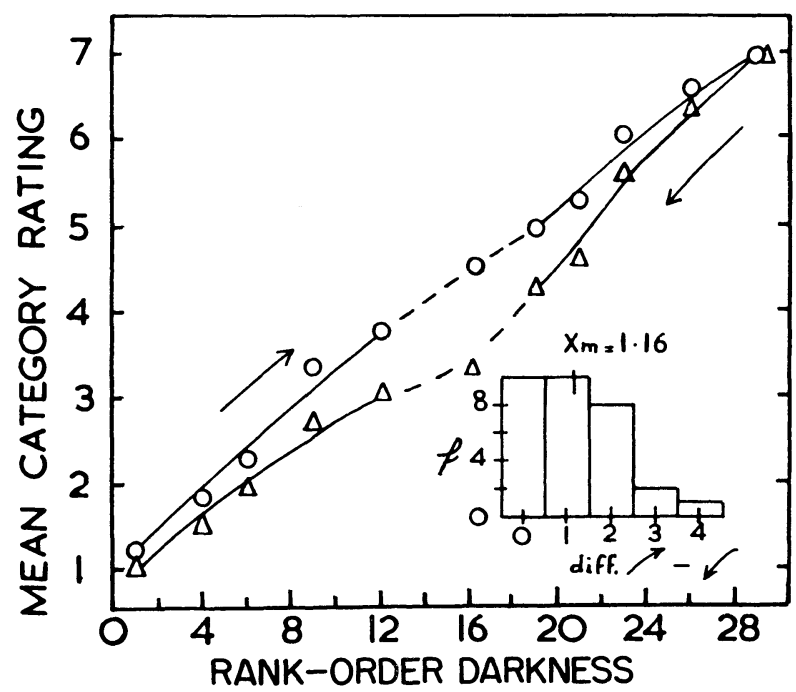

Fig. 1. The effect of order of presentation upon category estimation of grays. The insert represents the frequency distribution of differences of ratings assigned to the intermediate paper by 31 Ss under the two orders of presentation. intermediate gray under the two orderings by the $31 \mathrm{Ss}$. All rating differences were either zero or in the indicated direction. Inexperienced Ss probably would have obtained even larger differences.

The effect of the systematic order of presentation probably stems from S's tendency to assign different ratings to stimuli that are recognized as different (Stevens \& Galanter, 1957; Krantz \& Campbell, 1961). Thus, in the initial presentation of the light grays, the range of numbers assigned to the lighter set becomes expanded, with a corresponding contraction of the range of numbers available to accommodate the darker set. The converse is obtained when the darker set is presented initially.

\section{Experiment 2. Effect of First Response}

A single order or presentation of 11 grays, shown upon the upper abscissa of Fig. 2, was used with 45 naive Ss (Cambridge University students and visitors). Category ratings of 3,4 , and 5 to the first gray were given by 14 , 14 , and $15 \mathrm{Ss}$ respectively. (Ratings of 2 and 6 were each given by one S.) Each S was grouped by his first rating alone.

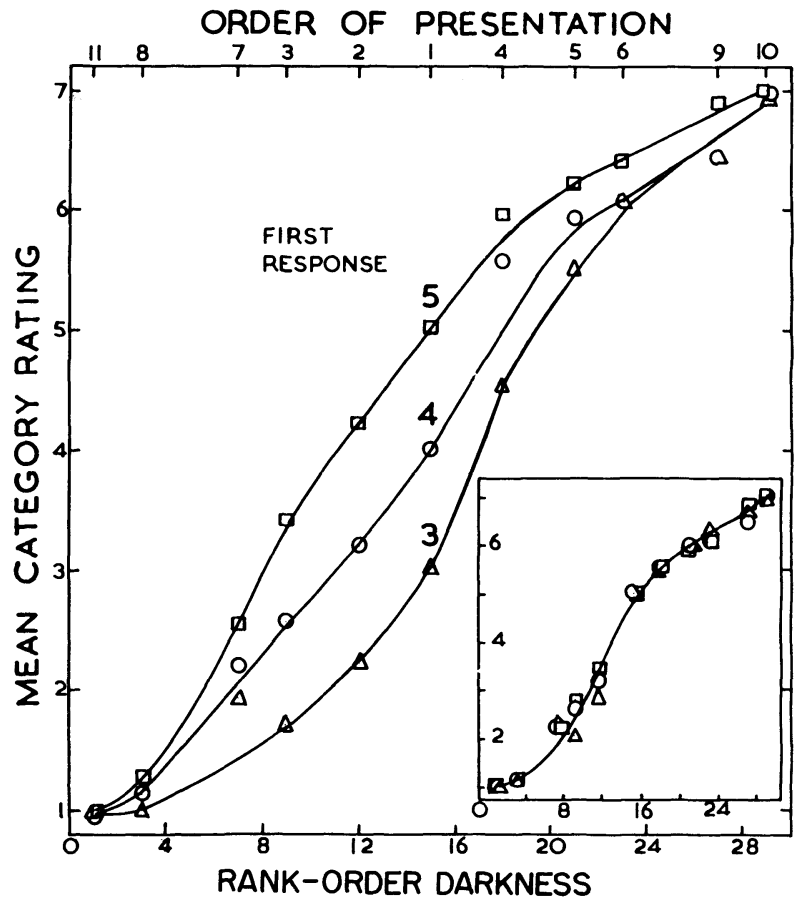

Fig. 2. The role of the first response in the category estimation of grays. The insert represents a category estimation, calculated on the assumptions that the first responses were identical and that the extremes remained fixed. 
Table 1. Mean Category Estimations Assigned to Six Gray Papers

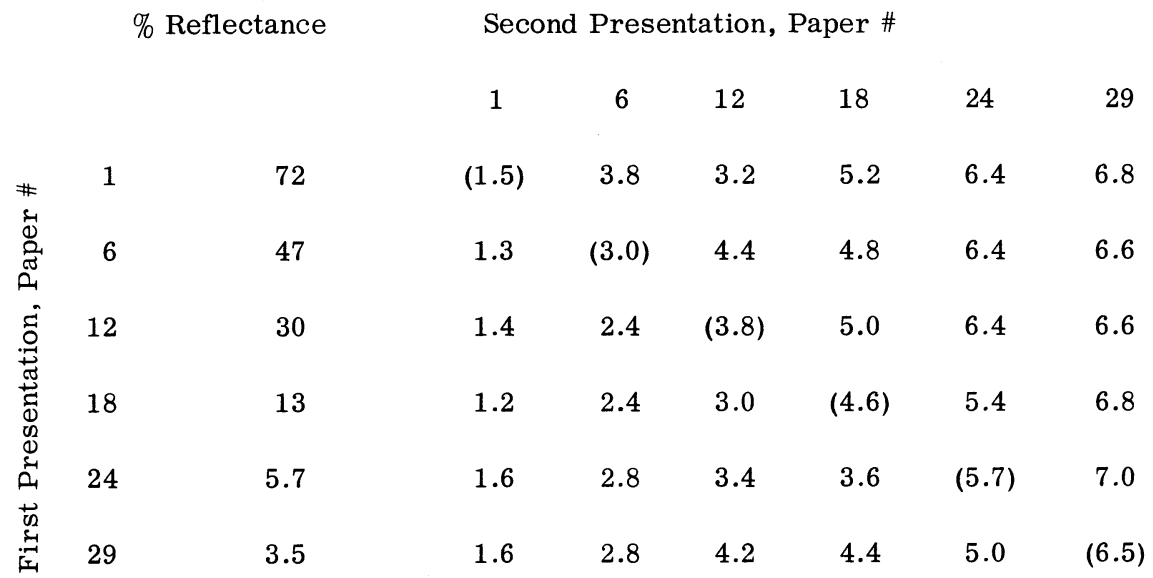

Figure 2 demonstrates that the entire category estimation function, with the exception of the extremes, is strongly determined by the first category rating alone. This is further illustrated by the insert of Fig. 2 which presents the resulting category estimation, calculated on the assumptions that the first responses were identical among Ss and that the ends of the category function remained fixed. Remaining deviations are associated with the ratings assigned to the second and third stimulus presentations, which nearly preserved the initial absolute differences on ratings.

\section{Experiment 3. Sequential Effects of Presentation}

For each of 30 groups of 5 naive Ss each (Cambridge University students), one of 6 grays was presented as the first stimulus and one of the 5 other grays was presented as the second stimulus for category rating. Table 1 examines the sequential effects of presentation. Entries within parentheses represent the mean category estimation by $25 \mathrm{Ss}$ to the first gray presented. Within each column, other entries represent the mean category estimation of $5 \mathrm{Ss}$ to a given gray, when preceded by that gray listed on the left. Entries above parentheses represent conditions in which the second paper was darker than the first; entries below parentheses repre-

sent conditions in which second paper was lighter than the first. The associated reflectances of the papers are also listed.

A systematic sequential contrast in the estimations is observed, especially where the second paper is not markedly different from the first. Entries above the parentheses tend to be higher, and entries below the parentheses tend to be lower, than the entries within parentheses. A given paper will thus be assigned a darker rating when preceded by a lighter paper and will be assigned a lighter rating when preceded by a darker paper.

\section{References}

KRANTZ, D. L., \& CAMPBELL, D. T. Separating perceptual and linguistic effects of context shifts upon absolute judgments. J. exp. Psychol., 1961, 62, 35-42. STEVENS, S. S., \& GALANTER, E. H. Ratio scales and category scales for a dozen perceptual continua. J. exp. Psychol., 1957, 54, 377-411.

\section{Note}

1. The experiments were performed under a National Sciences Foundation Postdoctoral Fellowship. The writer is grateful to Dr. Christopher Poulton for aid in assembling the subjects. 